\title{
THE PROPULSIVE SMALL EXPENDABLE DEPLOYER SYSTEM EXPERIMENT
}

\author{
Mr. Les Johnson \\ Mail Code RA10, NASA Marshall Space Flight Center \\ Huntsville, Alabama 35812 \\ 205-544-0614 (phone) 205-544-6669 (fax) \\ Drs. Robert D. Estes \& Enrico Lorenzini \\ Smithsonian Astrophysical Observatory \\ 60 Garden Street, Cambridge, Massachusetts 02138 \\ 617-495-7261 (phone) 617-496-7670 (fax) \\ Dr. Manuel Martinez-Sanchez \\ Massachusetts Institute of Technology \\ Cambridge, Massachusetts \\ 617-253-5613 (phone) 617-258-5143 (fax) \\ Dr. Juan Sanmartin \\ Polytechnic University of Madrid \\ Madrid, Spain
}

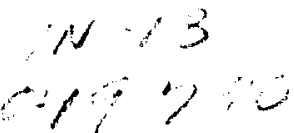

\begin{abstract}
$\underline{\text { Abstract }}$
Relatively short electrodynamic tethers can extract orbital energy to 'push' against a planetary magnetic field to achieve propulsion without the expenditure of propellant. The Propulsive Small Expendable Deployer System experiment will use the flight-proven Small Expendable Deployer System (SEDS) to deploy a $5 \mathrm{~km}$ bare copper tether from a Delta II upper stage to achieve $\sim 0.4 \mathrm{~N}$ drag thrust, thus lowering the altitude of the stage. The experiment will use a predominantly 'bare' tether for current collection in lieu of the endmass collector and insulated tether approach used on previous missions. The flight experiment is a precursor to a more ambitious electrodynamic tether upper stage demonstration mission which will be capable of orbit raising, lowering and inclination changes - all using electrodynamic thrust. The expected performance of the tether propulsion system during the experiment is described.
\end{abstract}

\section{Introduction}

Since the 1960's there have been at least 17 tether missions flown in space. In the 1990's, several important milestones were reached, including the retrieval of a tether in space (TSS-1, 1992), successful deployment of a 20-km-long tether in space (SEDS-1, 1993), closed loop control of tether deployment (SEDS-2, 1994) and operation of an electrodynamic tether with tether current driven in both directions-power and thrust modes (PMG, 1993). A list of known tether missions is shown in Table 1. The Propulsive Small Expendable Deployer System (ProSEDS) experiment will build upon the technology heritage of these missions and demonstrate the use of long electrodynamic tethers for space propulsion. This will be accomplished by deploying a 5-km bare-wire tether from the SEDS deployer and the subsequent collection of 1-2 Amperes of current from the ionosphere along the length of the tether. The interaction of the tether current with the Earth's magnetic field will produce a drag thrust, thus lowering the altitude of the upper stage by as much as 15 kilometers per day. Instrumentation will characterize ambient space plasma environment as well as the performance of the tether as a 
current collector under varied ionospheric conditions. The experiment is manifest for flight as a secondary payload aboard a Delta II rocket in August 2000.

TABLE 1: Summary of known space tether missions.

\begin{tabular}{|l|l|l|l|l|}
\hline NAME & DATE & ORBIT & LENGTH & COMMENTS \\
\hline Gemini 11 & 1966 & LEO & $30 \mathrm{~m}$ & spin stable 0.15 rpm \\
\hline Gemini 12 & 1966 & LEO & $30 \mathrm{~m}$ & local vertical, stable swing \\
\hline H-9M-69 & 1980 & suborbital & $500 \mathrm{~m}$ & partial deployment \\
\hline S-520-2 & 1981 & suborbital & $500 \mathrm{~m}$ & partial deployment \\
\hline Charge-1 & 1983 & suborbital & $500 \mathrm{~m}$ & full deployment \\
\hline Charge-2 & 1984 & suborbital & $500 \mathrm{~m}$ & full deployment \\
\hline ECHO-7 & 1988 & suborbital & $?$ & magnetic field aligned \\
\hline Oedipus-A & 1989 & suborbital & $958 \mathrm{~m}$ & spin stable 0.7 rpm \\
\hline Charge-2B & 1992 & suborbital & $500 \mathrm{~m}$ & full deployment \\
\hline TSS-1 & 1992 & LEO & $<1 \mathrm{~km}$ & electrodynamic, partial deploy, retrieved \\
\hline SEDS-1 & 1993 & LEO & $20 \mathrm{~km}$ & downward deploy, swing \& cut \\
\hline PMG & 1993 & LEO & $500 \mathrm{~m}$ & electrodynamic, upward deploy \\
\hline SEDS-2 & 1994 & LEO & $20 \mathrm{~km}$ & local vertical stable, downward deploy \\
\hline Oedipus-C & 1995 & suborbital & $1 \mathrm{~km}$ & spin stable 0.7 rpm \\
\hline TSS-1R & 1996 & LEO & $19.6 \mathrm{~km}$ & electrodynamic power generation and science \\
\hline TiPS & 1996 & LEO & $4 \mathrm{~km}$ & long life tether \\
\hline ATEx & 1999 & LEO & $<30 \mathrm{~m}$ & Incomplete deployment \\
\hline
\end{tabular}

\section{Electrodynamic Tether Propulsion Principles}

An electrodynamic tether generates and forms part of a unique type of electrical circuit, which has been successfully demonstrated in space. The tethered system extracts electrons from the ionospheric plasma at one end (upper or lower) and then carries the electrons through the tether to the other end, where it returns them to the plasma. The circuit is completed by currents in the plasma. The net force caused by a uniform magnetic field acting on a current-bearing closed loop of wire (i.e., a normal circuit) would be zero, as the force on one length of wire would be canceled by that on another in which the current was flowing in the opposite direction. However, since there is no mechanical attachment of the tethered system to the plasma (which is just the rarefied medium through which the system is traveling), magnetic forces on the plasma currents do not affect the tether motion. In other words, we have a length of wire with a unidirectional current flowing in it, and this wire is accelerated by Earth's magnetic field.

The bias voltage of a vertically deployed metal tether, which results just from its orbital motion through Earth's magnetic field, is positive with respect to the ambient plasma at the top and negative at the bottom. Thus, the "natural" current flow is the result of negative electrons being attracted to the upper end and then returned to the plasma at the lower end. For an eastwardmoving system, such as most Earth-orbiting spacecraft, the field is such that the electrical potential decreases with increasing altitude (at a rate of around $100 \mathrm{~V} / \mathrm{km}$ for a $400 \mathrm{~km}$ circular orbit). The magnetic force in this case has a component opposite to the direction of motion, and thus leads to a lowering of the orbit and eventually to re-entry. The basic physics was verified to work in space by the TSS-1R and PMG missions, but no measurements were made to quantify the resulting orbital changes nor was the high-current bare tether concept demonstrated. 
The motion of the system through the Earth's magnetic field induces a voltage $e m f=\mathbf{L} \cdot(\mathbf{v} \times \mathbf{B})$ between the two ends of the conductive tether, where $\mathbf{L}$ is a vector parallel to the tether and whose magnitude is the length of the conductive tether, $\mathbf{v}$ is the velocity of system through the ionosphere, and $\mathbf{B}$ is the local value of the Earth's magnetic field vector.

The current in the tether varies along its length, since collected electrons accumulate in an increasing downward stream in the wire. Denoting the current in a segment of tether $\Delta \ell$ at a distance $\ell$ from the lower end of the tether by $I(\ell)$, we have for the drag force on this tether segment $\mathbf{F}_{d}(\ell)=I(\ell) \Delta \vec{\ell} \times \mathbf{B}$, where $\Delta \vec{\ell}$ points in the direction of the current flow. The total drag force on the system is then the sum of the $\mathbf{F}_{d}(\ell)$ over the full tether length.

To get an orbit-raising thrust, a current in the opposite direction must be obtained. This requires a reversal of the natural electrical bias (i.e., that due to the motion through the magnetic field) by means of an electrical power supply, which can, of course, use solar energy. PMG has successfully demonstrated this mode of operation using batteries, though no thrust measurements were made.

One of the most important features of electrodynamic tether thrust is that no on-board power source is required to drive the electrical current flow in either the orbit-raising or orbit-lowering mode. Sources inherent to Earth orbit are used. To raise the orbit, the natural energy of the Sun can be converted to the electrical energy required to drive the tether current. To lower the orbit, the orbital energy itself (supplied by the Earth-to-orbit launcher when it raises the system into orbit) is the energy source of the tether current. ProSEDS will operate in the orbit-lowering mode. Rather than dissipating all the electrical energy it generates in its operation, ProSEDS will use some of it to recharge batteries.

The previously cited EDT missions, while verifying that the basic principles of EDT operation are sound, did not establish scalability of EDT to useful applications. ProSEDS aims to do this through the use of a more efficient current collection design.

For ProSEDS, the electron expulsion task will be handled by a hollow cathode device, which requires a small amount of gas to operate. In future applications, Field Emitter Arrays (FEAs) may eliminate the need for even this consumable.

Collecting electrons from the ionosphere proves to be much more difficult than expelling them into it. Previous experiments relied on either a large metallic surface (TSS-1R satellite) or a hollow cathode (PMG) to collect electrons from the ionosphere. PMG currents were disappointing. Achieving higher currents by satellite surface collection requires ever larger satellites, as a law of diminishing returns quickly sets in.

ProSEDS will use a radically different collection scheme, which promises to be much more efficient and easily scaleable to practical applications such as magnetic thrust. Most of the metallic tether will be left exposed to the plasma, rather than covered with an insulating sleeve as in previous EDT missions. The bare tether itself will collect electrons directly. A well developed theory of current collection by thin wires, verified in plasma chamber tests (most recently at MSFC), indicates that the ProSEDS tether will be an order of magnitude more efficient in electron collection than what has been seen in previous space experiments, with even greater enhancements possible in the future. Before we can proceed to the design of an operational system, however, we must test the bare tether design in LEO. So far, neither theory nor lab tests 
have modeled the effects of the motion of the tether through the plasma. While there is no obvious reason why this should significantly affect the current collection, prudence demands that we verify the bare tether's performance in space with a real deployed tether system. ProSEDS will provide that verification, and the data collected by the various ProSEDS instruments will thoroughly characterize the space environment, thus giving analysts a chance to determine the reasons for any deviations from predicted performance.

\section{The ProSEDS Experiment}

The ProSEDS experiment will be placed into a $400 \mathrm{~km}$ circular orbit as a secondary payload from a Delta II launch vehicle. Once on orbit, the SEDS will deploy $10 \mathrm{~km}$ of insulating Spectra tether attached to an endmass, followed by $5 \mathrm{~km}$ of predominantly bare wire tether. Upward deployment will set the system to operate in the generator mode, thus producing drag thrust and electrical power. The drag thrust provided by the tether, with an average current of $0.5 \mathrm{~A}$, will lower the altitude of the Delta II upper stage. (Figure ?) If the tether system were to survive the micrometeoroid, orbital debris and atomic oxygen environment, the stage would deorbit in approximately 17 days, versus its nominal $\geq 6$ months lifetime in a $400 \mathrm{~km}$ circular orbit.

Figure ?. The electrodynamic tether dramatically reduces the orbital lifetime of the upper stage.

The specific goals and success criteria for the experiment are described in Table 2. The thrust measurements will be accurately determined by measuring the change in orbital position of the stage using the Global Positioning System and through ground tracking. A Differential Ion Flux Probe (DIFP) and Langmuir Probe will be used to characterize the ambient plasma environment.

Table 2. ProSEDS experiment objectives.

\begin{tabular}{|c|c|c|c|}
\hline OBJECTIVES & $\begin{array}{l}\text { CRITERIA FOR SUCCESS } \\
\text { (PERFORMANCE METRICS) }\end{array}$ & $\begin{array}{l}\text { MEASUREMENTS } \\
\text { REQUIRED }\end{array}$ & $\begin{array}{l}\text { INSTRUMENTS } \\
\text { REQUIRED }\end{array}$ \\
\hline $\begin{array}{l}\text { (Primary) Demonstrate significant, } \\
\text { measurable electrodynamic tether } \\
\text { thrust in space. }\end{array}$ & $\begin{array}{l}\text { Demonstrate an orbital decay } \\
\text { rate of at least } 5 \mathrm{~km} \text { per day. }\end{array}$ & Change Of Orbital Position. & $\begin{array}{l}\text { GPS } \\
\text { Ground RADAR } \\
\text { Ground telescopes }\end{array}$ \\
\hline $\begin{array}{l}\text { (Primary) Measure the current } \\
\text { collection performance of the bare } \\
\text { electrodynamic tether under varied } \\
\text { ionospheric conditions and } \\
\text { determine its scalability to future } \\
\text { applications. }\end{array}$ & $\begin{array}{l}\text { Obtain data over } 16 \text { orbits. } \\
\text { (Obtain continuous data for } \\
\text { the first } 3 \text { orbits and sampling } \\
\text { over the remaining } 13 . \text { ) }\end{array}$ & $\begin{array}{l}\text { Voltage } \\
\text { Current } \\
\text { Magnetic Field Orientation } \\
\text { Spacecraft Potential } \\
\text { Plasma Density } \\
\text { Ambient Electron } \\
\text { Temperature } \\
\text { Absolute position of Delta } \\
\text { Relative position of Tether } \\
\text { (est) }\end{array}$ & $\begin{array}{l}\text { Voltmeter } \\
\text { Ammeter } \\
\text { Aspect Magnetometer } \\
\text { DIFP, Langmuir Probe } \\
\text { Langmuir Probe, DIFP } \\
\text { Langmuir Probe } \\
\text { GPS, Ground RADAR } \\
\text { Turns Counter }\end{array}$ \\
\hline $\begin{array}{l}\text { (Secondary) Demonstrate the } \\
\text { regulation, storage, and use of tether } \\
\text { generated electrical power. }\end{array}$ & $\begin{array}{l}\text { Generate a current of at least } \\
\text { 1.5 Amperes (orbital } \\
\text { average). }\end{array}$ & $\begin{array}{l}\text { Battery Temperature } \\
\text { Voltage } \\
\text { Current }\end{array}$ & $\begin{array}{l}\text { Thermistor } \\
\text { Voltmeter } \\
\text { Ammeter }\end{array}$ \\
\hline $\begin{array}{l}\text { (Secondary) Determine system } \\
\text { performance during the extended } \\
\text { mission phase (begins after orbit } \\
16 \text { ). }\end{array}$ & $\begin{array}{l}\text { Collect available tether } \\
\text { performance data. }\end{array}$ & $\begin{array}{l}\text { Telemetry (if available) } \\
\text { Change of Orbital Position }\end{array}$ & $\begin{array}{l}\text { All functioning instruments } \\
\text { GPS, Ground RADAR } \\
\text { Ground Telescopes }\end{array}$ \\
\hline $\begin{array}{l}\text { (Secondary) Assess tether } \\
\text { survivability in AO, meteoroid, and } \\
\text { orbital debris environment. }\end{array}$ & Observe tether integrity. & $\begin{array}{l}\text { Tether observation(s) } \\
\text { Voltage } \\
\text { Current }\end{array}$ & $\begin{array}{l}\text { GPS, RADAR \& telescopes } \\
\text { Voltmeter } \\
\text { Ammeter }\end{array}$ \\
\hline $\begin{array}{l}\text { (Secondary) Assess tethered } \\
\text { electrodynamic system operations }\end{array}$ & $\begin{array}{l}\text { Stable (bounded) dynamic } \\
\text { envelopes }\end{array}$ & $\begin{array}{l}\text { Endmass relative position and } \\
\text { attitude versus time }\end{array}$ & $\begin{array}{l}\text { GPS } \\
\text { Magnetometer }\end{array}$ \\
\hline
\end{tabular}


The rate of altitude change is strongly dependent upon the current collected by the tether, as can be seen in Figure ??. The current collection varies dramatically as a function of plasma density as well as the orientation of the tether with respect to the magnetic field. (Figure ???.) There are times in the orbit when both the induced emf and the plasma density are low, thus decreasing the thrust of the system. These two parameters are independent will be measured by on-board instrumentation. Performance and diagnostic instruments mounted on the Delta II will be used to correlate the propulsive forces generated by the electrodynamic tether and the existing plasma conditions. These instruments will measure plasma density, temperature, energy, and potential.

Figure ??. The orbital lifetime of the stage versus orbital average current collected.

Fig. ???. Current at Delta vs. mission elapsed time

\section{POTENTIAL APPLICATIONS OF THE TECHNOLOGY}

The primary advantage of electrodynamic tethers is that they can be used as propellantless (no resupply required) space propulsion systems. Tethers take advantage of the natural plasma environment and sunlight to provide thrust and power. For example, if solar arrays and an external power supply are used, an emf can be generated in the tether such that current collected from the ionosphere produces thrust rather than drag. This thrust can then be used to raise the orbit of the system or change its inclination - all without propellant or rocket engines. It is envisioned that this type of propulsion could be used on a reusable upper stage to provide a low cost alternative to chemical stages. An electrodynamic tether upper stage could be used as an orbital tug to move payloads within low earth orbit (LEO) after insertion. The tug would rendezvous with the payload and launch vehicle, dock/grapple the payload and maneuver it to a new orbital altitude or inclination within LEO without the use of boost propellant. The tug could then lower its orbit to rendezvous with the next payload and repeat the process. Such a system could conceivably perform several orbital maneuvering assignments without resupply, making it low recurring cost space asset. A follow-on mission to the ProSEDS is being considered to demonstrate the orbit raising and lowering capabilities of electrodynamic tethers. The project, tentatively called STEP (Space Transfer using Electrodynamic Tethers) would be a 500-kg class satellite with dual tethers and an on-board power system. It's expected performance is illustrated in Figure ????

Figure ???? Estimated propulsive performance of an upper stage demonstrator vehicle using electrodynamic tether thrust. 


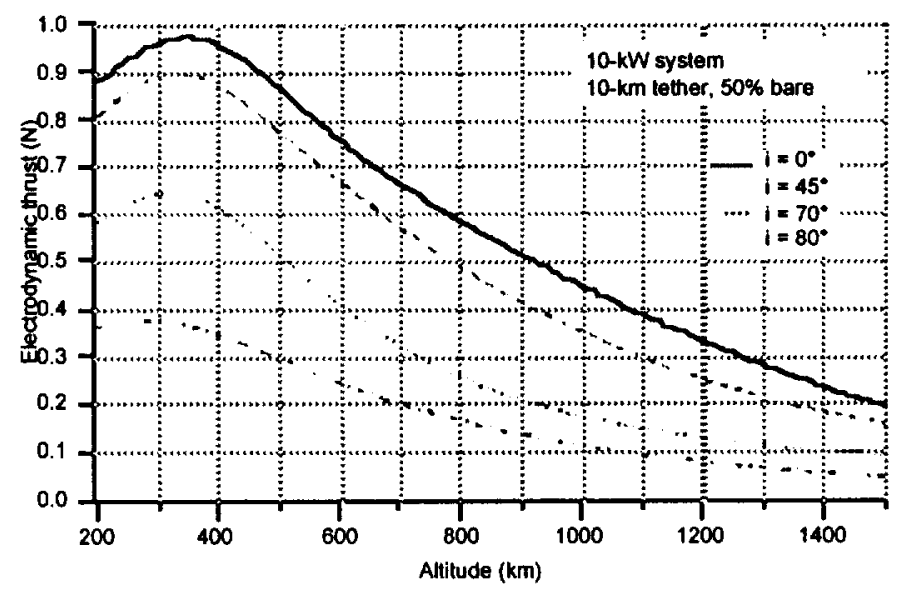

A ProSEDS-derived system could be used operationally to extend the capability of existing launch systems by providing a propellantless system for deorbiting spent stages. The launch service provider need not carry additional fuel for the soon-to-be-required deorbit maneuver, thus allowing all the onboard fuel to be used for increasing the vehicle's performance. Similarly, satellites thus equipped could safely deorbit at their end of life without using precious onboard propellant. Both of these applications would help reduce the increasing threat posed by orbital debris.

An electrodynamic tether system might also be used on the International Space Station (ISS) to supply a reboost thrust of $0.5-0.8 \mathrm{~N}$, thus saving up to $6000 \mathrm{~kg}$ of propellant per year. The reduction of propellant needed to reboost the ISS equates to a $\$ 2 \mathrm{~B}$ savings over it's 10 year lifetime ${ }^{4}$. Other advantages of using the electrodynamic tether on ISS are that the microgravity environment is maintained and external contaminants are reduced.

\section{Conclusions}

Tether technology has advanced significantly since its inception over 30 years ago. The recent successes of the SEDS system show that tethers are ready to move from experiment and demonstration to application. One of the most promising applications for tethers is space propulsion and transportation. The ProSEDS mission will demonstrate the ability of an electrodynamic tether to produce thrust by lowering the altitude of a Delta II rocket. It's performance as a propulsion system is heavily dependent on the ambient environmental conditions (plasma conditions and magnetic field strength). 